\title{
Predictors and burden of injury mortality in the Thai cohort study 2005-2015
}

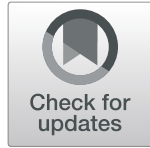

\author{
C. T. Lowe ${ }^{1 *}$ (D) M. Kelly ${ }^{1}$, S. Seubsman² and A. Sleigh ${ }^{1}$
}

\begin{abstract}
Background: Thailand is a high injury burden setting. In 2015 it had the world's second highest rate of road traffic fatalities. In order to develop strategies to reduce this burden an accurate understanding of the development of injury risk over the life course is essential.

Methods: A national cohort of adult Thais was recruited in $2005(n=87,151)$. Participants completed a health questionnaire covering geodemographic, behavioural, health and injury data. Citizen ID numbers were matched with death registration records, identifying deaths from any injury. Adjusted logistic regression models were used to measure associations between baseline exposures and injury deaths between 2005 and 2015.

Results: Injury mortality comprised 363 individuals, the majority (36\%) from traffic injuries. Predictors of all-injury mortality were being male (AOR 3.55, 95\% Cl 2.57-4.89), Southern Thai (AOR 1.52, 95\% Cl 1.07-2.16), smoking (AOR 1.55, 95\% Cl 1.16-2.17), depression (AOR 1.78, 95\% Cl 1.07-2.96), previous injury (AOR 1.37, 95\% Cl 1.03-1.81) and drink driving history (AOR 1.37,95\% $\mathrm{Cl} 1.02-1.85$ ). Age and region of residence were stronger predictors for men, while anxiety/depression was a stronger predictor for women. Among males in the far south, assault caused the largest proportion of injury mortality, elsewhere traffic injury was most common.
\end{abstract}

Conclusions: This study identifies that a history of drink driving, but not regular alcohol consumption, increased injury risk. The associations between smoking and depression, and injury mortality also need further consideration.

Keywords: Mortality, Cohort study, Epidemiology, Risks/ determinants, Low-middle income country

\section{Background}

Injury causes significant morbidity and mortality globally. Approximately one-tenth of global deaths are injury-related [1], and road traffic injuries proceeded by suicide were the fourth and sixth leading causes of death globally for 15-49 year olds in 2017 [2]. Injury deaths may also include poisonings, falls, fire-related deaths, drowning, intentional self-harm, assault as well as other un-intentional injuries. The distribution of injuries however is not equal globally; approximately $90 \%$ of all injury deaths occur in low- and middle-income countries $[1,3]$.

\footnotetext{
*Correspondence: callum.t.lowe@gmail.com; u6383754@anu.edu.au ${ }^{1}$ Department of Global Health, Research School of Population Health, Australian National University, 339/4 Hutton St, Acton ACT 2601, Australia Full list of author information is available at the end of the article
}

In recent decades in high income countries the implementation of interventions such as speed limit enforcement, drink-driving testing and smoke detectors has led to a reduction in the burden of injuries [1]. Impeding on the ability for the governments of low and middle income countries to design effective injury-prevention strategies is the lack of data, evidence [3] and resources [4]. Often the processes of recording data for injury deaths in these countries are not complete, police reports, hospital based data and national vital registration statistics regularly are not integrated and have large discrepancies in reporting the burden of injury deaths and lead to an under-represented figure. As such the burden of injuries, the relative burden of various injury classifications, and the distribution of injury burden amongst population sub-groups are still poorly understood in

(c) The Author(s). 2020 Open Access This article is licensed under a Creative Commons Attribution 4.0 International License, which permits use, sharing, adaptation, distribution and reproduction in any medium or format, as long as you give appropriate credit to the original author(s) and the source, provide a link to the Creative Commons licence, and indicate if changes were made. The images or other third party material in this article are included in the article's Creative Commons licence, unless indicated otherwise in a credit line to the material. If material is not included in the article's Creative Commons licence and your intended use is not permitted by statutory regulation or exceeds the permitted use, you will need to obtain permission directly from the copyright holder. To view a copy of this licence, visit http://creativecommons.org/licenses/by/4.0/ The Creative Commons Public Domain Dedication waiver (http://creativecommons.org/publicdomain/zero/1.0/) applies to the data made available in this article, unless otherwise stated in a credit line to the data. 
low- and middle-income countries. Furthermore, injuries are a difficult cause of death to monitor because of the complexities associated with defining the specific cause of injury death. One problem often contributing to injury death rates being underestimated is when a death occurs due to an injury, however only the immediate cause of the injury is recorded as the cause of death (bleeding, fractures etc.) and the underlying cause of an injury (traffic accident, fall, assault etc.) is lost in health data.

Thailand, a south-east Asian country, has been reported as a major contributor of global injury mortality. Thailand has been reported to have the highest rate of road-traffic accidents globally ( 36.2 per 100,000 population in 2015) [5]. Increasing mortality due to road-traffic accidents in such low- and middle-income countries has been attributed to rapid economic development which has outpaced road infrastructure development and safety provisions [6]. As an ageing population, fall-deaths among the elderly also contribute to injury mortality in Thailand [7]. Furthermore, many injury deaths are initially recorded with undetermined intent [8] and many with no known underlying injury. However, studies using verbal autopsies to investigate details surrounding injury deaths have resulted in more specific cause of death data in Thailand. In particular, deaths due to suicide, assault and drowning have been more accurately estimated [9]. Other studies have resulted in an increase of mortality cases being assigned to road-traffic injury through examining details of these non-specific cause fatalities [10]. It has also been found in Thailand that physicians who were young and inexperienced and older physicians frequently mis-classified the underlying cause of deaths [8]. Techniques for re-distributing the classification of non-specific injury deaths into specific underlying causes have been developed in order to improve the validity of injury-burden calculations, one such technique using demographics and characteristics of groups with known-cause injury deaths and comparing these characteristics with unknown-cause injury deaths for allocation [11].

After an accurate calculation of the burden of injury in Thailand, understanding risk factors and socio/geodemographic groups at high risk to injury mortality assists in developing effective injury prevention strategies. Alcohol use, [12] depression, [13, 14] and smoking incidence [15] have consistently been reported as risk factors for injury mortality. Young males are consistently reported as the demographic with highest risk of injury mortality in Thailand [16]. Alcohol is a major risk factor for injury mortality for all demographics of any population, and this risk is particularly dangerous for road-traffic accidents as it negatively effects drivers' judgement and reaction time [17].
As such, we aim to investigate long-term risk factors for injury mortality in Thailand and the distribution of various injury types. In doing so, we can identify specific demographics and risk factors towards injury mortality later in an individual's life. Thus, interventions towards injury mortality in Thailand can be developed in order to reduce the burden of injury mortality and particularly pre-mature death due to injury. Our research here is an extension to our prior work on injury deaths in the Thai Cohort Study (TCS), a study of 87,134 students enrolled at Sukhothai Thammathirat Open University (STOU). We have previously investigated injury mortality in our cohort for deaths occurring between 2005 to 2010 [4]. Here, we extend our research to cover deaths from 2005 to 2015 to investigate the burden of and risk factors for injury mortality in the cohort.

\section{Methods}

\section{Study population and data collection}

This analysis is part of the Thai Cohort Study (TCS); a longitudinal epidemiological investigation of health risks and outcomes in Thailand. A cohort of 87,134 distancelearning students residing all over Thailand enrolled at Sukhothai Thammathirat Open University (STOU) who completed the baseline mail-out 20-page health questionnaire in 2005 forms the study population for this analysis. This questionnaire was mailed to approximately 200,000 STOU students and by February 2006 a total of 87,134 had returned completed questionnaires and consent forms.

At baseline the cohort members were aged between 15 and 87 years and were similar to the general Thai population in terms of median age ( 29 years), sex distribution (54\% female compare to $51 \%$ in general population), median income (USD2550 vs USD 2742 in the general population), religion (94\% Buddhist in both populations) and geographic distribution across regions of Thailand. The cohort was however 51\% urban versus $31 \%$ in the general population, had a younger overall age structure with $52 \%$ being aged between 20 and 29 years, and had a higher average level of education ( $96 \%$ had finished high school, versus $21 \%$ in the national population in 2005) [18].

Questions were split into multiple categories, including 'You and your home', 'Income and work', 'Your health, injuries and health service use', 'Social networks and well-being', 'Food and physical activity', 'Tobacco, alcohol and transport' and 'Your family'.

\section{Mortality data}

Our analysis involved measuring associations between demographic and health-risk factors from baseline in 2005 and mortality between 2005 and 2015. Mortality data was obtained using the Thai citizen ID number 
provided by all participants at baseline. At various time points, the citizen ID numbers of participants in the cohort were matched with the Thai Ministry of Interior to obtain lists of participants in the cohort who had died by the time point. This list was then sent to the Thai Ministry of Public Health, where the WHO ICD code (International Classification of Disease code) was added to provide information on the cause of death. A previous paper has been published on injury mortality deaths up to 2010 (total 204) within the cohort (Yiengprugsawan et al., 2014). We now have data on deaths occurring in the cohort up to 2016. We observed 1232 deaths up to December 2015, 363 (29.5\%) of which were injury deaths. For a death to be classified as an injury death in our analysis, it had to have an ICD-10 code for cause of death included in and between chapters $\mathrm{V}$ to $\mathrm{Y}$. These deaths were further grouped into a condensed list, consisting of Transport accidents, Assault, Intentional self-harm, Drowning, Falls, Exposure to smoke, fire and flames, and All other external causes.

\section{Exposures and confounders}

Exposures and confounders of interest to our analysis included geo-demographic and health-risk variables. Age was stratified and calculated as the age at midpoint (2010) as this best represents the distribution of the ageing cohort over the 10 -year period. It was not practical to measure age as a continuous variable because the association with age and the log odds of injury mortality was not linearly related. Other geo-demographic variables included sex, current residence (urban/rural as well as region) at baseline, highest education level excluding participation at STOU, and personal monthly income.

Health-risk variables we were interested in included alcohol drinking habits (never, occasional drinkers and regular drinkers), smoking (never smoked, have quit smoking before baseline, current smokers at baseline), drink-driving (question posed as having drunk 3 or more glasses of alcohol and then driven a motor vehicle in the 12 months prior to answering the survey at baseline), a doctor diagnosis of anxiety/depression, as well as reporting having experienced non-fatal injuries in the 12 months prior to baseline.

\section{Data processing and statistical analysis}

Analysis of variables was performed in SPSS software (SPSS) [19].

We first quantified the distribution of the condensed causes of injury mortality in the cohort (Transport accidents, Assaults, Intentional self-harm, Accidental drowning, Falls, Smoke, fire and flames and All other and external causes).

Next, we proceed to analysis for risk factors and geodemographic groups at higher risk for injury mortality in the cohort. First, the distribution of mortality by baseline social and demographic attributes was calculated, as well as for all exposures and confounders of interest. The variables chosen to include in analysis were determined by prior literature review, as well as having an initial significant association with injury death. Crude odds ratios and corresponding $p$-values were calculated. Predictors of injury mortality that had significant associations $(p<$ 0.05 ) with injury mortality in this initial analysis were incorporated into a binary logistic regression for injury mortality in the cohort where we present a fully mutually-adjusted odds ratio. A cox regression was calculated with the same variables as those entered in the final binary logistic regression. Adjusted hazard ratios were close to one, indicating no association between survival time and injury mortality. As such, no survival analysis is included in this report. We then performed a multivariate logistic regression for injury/non-injury mortality, both for the entire cohort and stratified by sex, calculating crude and adjusted odds ratios. Reference category for the outcome variable is being alive by endpoint.

\section{Ethics approval}

Ethics approval was obtained from Sukhothai Thammathirat Open University Research and Development Institute (protocol 0522/10) and the Australian National University Human Research Ethics Committee (protocols 2,004,344 and 2009/570). Informed written consent was obtained from all participants. In the baseline recruitment process participants were requested to provide their Citizen Identification Number and informed that the study would use this to identify vital events among the participants. The number was supplied voluntarily. These confidential ID numbers were safeguarded and stored at STOU in a secure office on the main campus with $24 \mathrm{~h}$ guards on patrol. The working files of these data were de-identified and no individual information will be released or displayed in any format.

\section{Results}

In Table 1 we present the distribution of injury causes in the cohort. From 2005 to 2015, there were 363 deaths in the cohort which accounted for approximately a quarter of all deaths. Of all injury deaths, about one third were due to all other external causes (predominantly unknown-cause injuries) and a third were transport accidents. Following transport accidents was assault making up about $11.6 \%$ of all injuries, intentional self-harm making up about 7\%, accidental drowning (5\%) and a very small number of falls and smoke/fire/flames deaths.

In Table 2, we first present the distribution of injury deaths in the cohort by all risk factors and present the crude odds ratio, and then proceed with the findings 
Table 1 Distribution of injury mortality by underlying injury cause, Thai Cohort Study 2005-2015

\begin{tabular}{ll}
\hline Cause of injury death & $\mathbf{n}(\%)$ \\
\hline Transport accident & $131(36.1)$ \\
Assault & $42(11.6)$ \\
Intentional self-harm & $26(7.2)$ \\
Accidental drowning & $18(5.0)$ \\
Falls & $7(1.9)$ \\
Exposure to smoke, fire and flames & $2(0.6)$ \\
All other external causes & $137(37.7)$ \\
Total & $363(100.0)$ \\
\hline
\end{tabular}

from a fully-adjusted multivariate logistic regression model for injury/non-injury mortality. Risk factors for injury mortality initially included age above 60 years, male sex, rural and southern Thailand residence, historical smoking and alcohol consumption, anxiety/depression, injury history and drink-driving history. University and diploma/certificate education were a protector for injury mortality. When all variables were incorporated into a fully mutually-adjusted model, male sex (AOR 3.39, 95\% CI 2.47-4.66), southern regency (AOR 1.52, 95\% CI 1.06-2.16), baseline smoker status (AOR 1.52, 95\% CI 1.09-2.11), anxiety/depression (AOR 1.87, 95\% CI 1.07-2.96), injury history (AOR 1.37, 95\% CI 1.031.81) and drink-driving (AOR 1.37, 95\% CI 1.14-3.07) remained significant predictors of injury mortality. Alcohol consumption was confounded by male sex and education was confounded by age (data not shown). Overall, male sex had the strongest association with injury mortality, and was more strongly associated with injury mortality (AOR 3.39) than non-injury mortality (AOR 1.43). Smoking, anxiety/depression and prior injuries also had an association with non-injury mortality in the fully adjusted model, however drink-driving was protective to non-injury mortality.

In Table 3, we present the results from a multivariate logistic regression for injury/non-injury mortality among females with the same variables as those presented in Table 2 excluding urban/rural residence. Southern region residency and smoking were not significant predictors among females, however those who reported occasionally drinking alcohol had half the odds of injury mortality compared to females who have never drunk alcohol (AOR 0.52, 95\% CI 0.31-0.86). Anxiety/Depression was also a stronger predictor in females (AOR 2.98, 95\% CI 1.35-6.58). Prior injuries was no longer associated with injury mortality, but was associated with noninjury mortality (AOR 1.65, 95\% CI 1.22-2.23).

Results from the multivariate logistic regression for injury/non-injury mortality among males is presented in Table 4. Whilst adjusted odds of non-injury mortality increased with age, middle-age was protective to injury mortality (AOR 0.53 , 95\% CI $0.33-0.85$ for injury mortality among 45-59 year olds compared to 15-29 year olds). Residing in southern Thailand remained significantly associated with injury mortality (AOR 1.79, 95\% CI 1.20-1.68), as well as currently smoking at baseline (AOR 1.51, 95\% CI 1.08-2.12). Anxiety/Depression was no longer significantly associated with injury mortality in males, but was significantly associated with noninjury mortality (AOR 1.71, 95\% CI 1.09-2.66). Drinkdriving was significantly associated with injury mortality (AOR 1.37, 95\% CI 1.00-1.87), and protected against non-injury mortality, however this was not statistically significant (AOR 0.81, 95\% CI 0.64-1.02).

\section{Discussion}

Our analysis of injuries in the Thai Cohort Study found 363 injury deaths occurring between 2005 and 2015, $78 \%$ more deaths than those included in our previous report for injury deaths between 2005 - March 2010.

After mutually adjusting for all covariates, risk factors with a statistically significant association with injury mortality were being male, drink driving, current smoker status at baseline, a diagnosis of anxiety/depression, a history of injuries and residing in the south (Table 2). Being aged $60+$ had strong adjusted odds of injury mortality (AOR 1.95) compared to those aged 15-29, however this association was not statistically significant. When the multivariate analysis was stratified by sex, among males, those aged between 30 and 59 had significantly smaller odds of injury mortality compared to younger participants. Smoking at baseline, southern border residency and drink driving remained significant predictors of injury mortality, whilst anxiety/depresson and prior injury were positive predictors but not statistically significant, likely due to smaller numbers after stratifying by sex (Table 4). Among females, drink-driving, smoking at baseline and prior injuries were positive but insignificant predictors of injury mortality, likely due to very few female injury deaths in the cohort. Anxiety/Depression was a bigger predictor of injury mortality in females (AOR 2.98, 95\% CI 1.35-6.58) than in males. Females whose highest education level was a diploma/certificate had twice the odds of injury mortality compared to university educated females, and occasional alcohol drinkers had half the odds of injury mortality compared to females who reported never having drunk alcohol.

Interestingly, drink-driving was a significant predictor of injury mortality in the cohort, but historical alcohol consumption was not. Alcohol is widely recognised as a risk factor for injury mortality [20]. Most studies that evaluate this association measure alcohol consumption around the time of an injury, such as $6 \mathrm{~h}$ prior [21] or the bloodalcohol concentration immediately after an injury [22] 
Table 2 Multivariate predictors for injury and non-injury mortality, Thai Cohort Study

\begin{tabular}{|c|c|c|c|c|c|c|}
\hline & \multicolumn{4}{|c|}{ Univariate $^{\mathbf{b}}$} & \multicolumn{2}{|l|}{ Multivariate $^{\mathbf{b}}$} \\
\hline & \multicolumn{2}{|c|}{ Injury mortality } & \multicolumn{2}{|c|}{ Non-injury mortality } & \multirow{2}{*}{$\begin{array}{l}\text { Injury mortality } \\
\text { AOR }(95 \% \mathrm{Cl})\end{array}$} & \multirow{2}{*}{$\begin{array}{l}\text { Non-injury mortality } \\
\text { AOR }(95 \% \mathrm{Cl})\end{array}$} \\
\hline & n (\%) & OR $(95 \% \mathrm{Cl})$ & n (\%) & OR $(95 \% \mathrm{CI})$ & & \\
\hline \multicolumn{7}{|l|}{ Age group } \\
\hline $15-29$ & $104(0.4)$ & - & $100(0.4)$ & - & - & - \\
\hline $30-44$ & $196(0.4)$ & $0.91(0.7-1.2)$ & $403(0.8)$ & $1.95(1.6-2.4)$ & $0.77(0.59-1.01)$ & $1.73(1.35-2.20)$ \\
\hline $45-59$ & $53(0.4)$ & $1.02(0.7-1.4)$ & $285(2.3)$ & $5.71(4.5-7.1)$ & $0.79(0.53-1.18)$ & $4.57(3.51-5.94)$ \\
\hline $60+$ & $10(1.3)$ & $3.28(1.7-6.3)$ & $81(10.2)$ & $27.59(20.6-37.8)$ & $1.95(0.77-4.91)$ & $18.36(12.4-27.0)$ \\
\hline \multicolumn{7}{|l|}{ Sex } \\
\hline Male & $280(0.7)$ & $4.14(3.2-5.3)$ & $575(1.5)$ & $2.40(2.1-2.8)$ & $3.39(2.47-4.66)$ & $1.43(1.16-1.76)$ \\
\hline Female & $83(0.2)$ & - & $294(0.6)$ & - & - & - \\
\hline \multicolumn{7}{|l|}{ Highest education } \\
\hline Junior High School & $20(0.7)$ & - & $73(2.4)$ & - & - & - \\
\hline High School & $194(0.5)$ & $0.73(0.5-1.2)$ & $388(1)$ & $0.40(0.3-0.5)$ & $1.01(0.54-1.89)$ & $0.82(0.58-1.15)$ \\
\hline Dip./Cert. ${ }^{a}$ & $96(0.4)$ & $0.61(0.4-1.0)$ & $213(0.9)$ & $0.37(0.3-0.5)$ & $1.13(0.59-2.14)$ & $0.90(0.63-1.28)$ \\
\hline University & $53(0.3)$ & $0.38(0.2-0.6)$ & $192(0.9)$ & $0.37(0.3-0.5)$ & $0.70(0.36-1.37)$ & $0.67(0.47-0.95)$ \\
\hline \multicolumn{7}{|l|}{ Home location } \\
\hline Urban & $159(0.4)$ & - & $422(0.9)$ & - & - & - \\
\hline Rural & $201(0.5)$ & $1.36(1.1-1.7)$ & $438(1.1)$ & $1.12(0.9-1.3)$ & $1.18(0.92-1.52)$ & $1.19(1.00-1.41)$ \\
\hline \multicolumn{7}{|l|}{ Region } \\
\hline Central/East & $94(0.4)$ & - & $231(0.9)$ & - & - & - \\
\hline Bangkok & $43(0.3)$ & $0.82(0.6-1.2)$ & $156(1.1)$ & $1.21(0.9-1.5)$ & $1.01(0.68-1.52)$ & $1.17(0.91-1.50)$ \\
\hline North & $70(0.4)$ & $1.26(0.9-1.7)$ & $165(1)$ & $1.20(0.9-1.5)$ & $1.17(0.83-1.66)$ & $1.09(0.86-1.39)$ \\
\hline Northeast & $85(0.5)$ & $1.33(0.9-1.8)$ & $210(1.2)$ & $1.34(1.1-1.6)$ & $1.02(0.72-1.43)$ & $1.25(1.00-1.56)$ \\
\hline South & $69(0.6)$ & $1.73(1.3-2.4)$ & $100(0.9)$ & $1.02(0.8-1.3)$ & $1.52(1.06-2.16)$ & $1.12(0.86-1.46)$ \\
\hline \multicolumn{7}{|l|}{ Smoking } \\
\hline Currently & $94(1.1)$ & $3.76(2.9-4.8)$ & $179(2)$ & $2.99(2.5-3.6)$ & $1.52(1.09-2.11)$ & $1.84(1.43-2.36)$ \\
\hline Quit & $79(0.5)$ & $1.87(1.4-2.4)$ & $233(1.6)$ & $2.30(1.9-2.7)$ & $0.87(0.62-1.23)$ & $1.22(0.97-1.55)$ \\
\hline Never & $178(0.3)$ & - & $427(0.7)$ & - & - & - \\
\hline \multicolumn{7}{|l|}{ Alcohol consumption } \\
\hline Regularly & $33(0.8)$ & $2.87(1.8-4.4)$ & $86(2.1)$ & $2.80(2.2-3.6)$ & $0.83(0.48-1.41)$ & $1.34(0.96-1.88)$ \\
\hline Occasionally & $212(0.4)$ & $1.47(1.1-1.9)$ & $448(0.9)$ & $1.16(0.9-1.4)$ & $0.79(0.56-1.11)$ & $0.88(0.71-1.08)$ \\
\hline Never & $64(0.3)$ & - & $171(0.8)$ & - & - & - \\
\hline \multicolumn{7}{|l|}{ Anxiety/Depression } \\
\hline Yes & $22(0.7)$ & $1.83(1.2-2.8)$ & $43(1.4)$ & $1.48(1.1-2.0)$ & $1.87(1.14-3.07)$ & $1.53(1.07-2.19)$ \\
\hline No & $341(0.4)$ & - & $823(1)$ & - & - & - \\
\hline \multicolumn{7}{|l|}{ Prior injuries } \\
\hline One or more & $84(0.6)$ & $1.54(1.2-1.9)$ & $188(1.3)$ & $1.47(1.2-1.7)$ & $1.34(1.02-1.77)$ & $1.37(1.13-1.66)$ \\
\hline None & $265(0.4)$ & - & $624(0.9)$ & - & - & - \\
\hline \multicolumn{7}{|l|}{ Drink driving } \\
\hline Yes & $159(0.7)$ & $2.30(1.9-2.8)$ & $256(1.2)$ & $1.24(1.1-1.4)$ & $1.38(1.03-1.85)$ & $0.78(0.64-0.96)$ \\
\hline No & $200(0.3)$ & - & $598(0.9)$ & - & - & - \\
\hline
\end{tabular}

${ }^{\mathrm{a} D i p l o m a / C e r t i f i c a t e . ~}{ }^{\mathrm{b}}$ Reference category is being alive by endpoint Odds ratios in bold typeface are statistically significant at $p<0.05$ 
Table 3 Multivariate predictors for injury and non-injury mortality among females, Thai Cohort Study

\begin{tabular}{|c|c|c|c|c|c|c|}
\hline & \multicolumn{4}{|c|}{ Univariate $^{b}$} & \multicolumn{2}{|l|}{ Multivariate $^{\mathbf{b}}$} \\
\hline & \multicolumn{2}{|c|}{ Injury mortality } & \multicolumn{2}{|c|}{ Non-injury mortality } & \multirow{2}{*}{$\begin{array}{l}\text { Injury mortality } \\
\text { AOR }(95 \% \mathrm{Cl})\end{array}$} & \multirow{2}{*}{$\begin{array}{l}\text { Non-injury mortality } \\
\text { AOR }(95 \% \mathrm{Cl})\end{array}$} \\
\hline & n (\%) & OR (95\% Cl) & n (\%) & OR $(95 \% \mathrm{Cl})$ & & \\
\hline \multicolumn{7}{|l|}{ Age } \\
\hline $15-29$ & $29(0.2)$ & - & $53(0.3)$ & - & - & - \\
\hline $30-44$ & $40(0.2)$ & $0.83(0.5-1.3)$ & $165(0.6)$ & $1.88(1.4-2.6)$ & $1.08(0.64-1.82)$ & $1.89(1.36-2.64)$ \\
\hline $45-59$ & $14(0.3)$ & $1.59(0.8-3.0)$ & $73(1.5)$ & $4.54(3.2-6.5)$ & $1.94(0.95-3.93)$ & $4.75(3.23-6.99)$ \\
\hline $60+$ & $0(0)$ & 0 & $3(1.8)$ & $5.36(1.7-17.3)$ & - & 7.07 (2.15-23.2) \\
\hline \multicolumn{7}{|l|}{ Education } \\
\hline Junior High School & $1(0.1)$ & - & $7(0.7)$ & - & - & - \\
\hline High School & $36(0.2)$ & $1.96(0.3-14.3)$ & $136(0.7)$ & $1.06(0.5-2.3)$ & $1.54(0.20-11.4)$ & $1.20(0.55-2.62)$ \\
\hline Dip./Cert. ${ }^{a}$ & $32(0.2)$ & $2.34(0.3-17.2)$ & $86(0.6)$ & $0.90(0.4-1.9)$ & $2.16(0.29-16.0)$ & $1.07(0.48-2.36)$ \\
\hline University & $14(0.1)$ & $1.22(0.2-9.3)$ & $64(0.5)$ & $0.79(0.4-1.7)$ & $1.03(0.13-8.00)$ & $0.72(0.32-1.62)$ \\
\hline \multicolumn{7}{|l|}{ Region } \\
\hline Central/East & $24(0.2)$ & - & $84(0.6)$ & - & - & - \\
\hline Bangkok & $10(0.1)$ & $0.70(0.3-1.5)$ & $72(0.8)$ & $1.43(1.0-2.0)$ & $0.71(0.32-1.55)$ & $1.21(0.85-1.72)$ \\
\hline North & $17(0.2)$ & $1.33(0.7-2.5)$ & $49(0.6)$ & $1.10(0.8-1.6)$ & $1.36(0.69-2.66)$ & $1.12(0.76-1.66)$ \\
\hline Northeast & $19(0.2)$ & $1.42(0.8-2.6)$ & $46(0.5)$ & $0.98(0.7-1.4)$ & $1.32(0.69-2.54)$ & $1.01(0.68-1.50)$ \\
\hline South & $12(0.2)$ & $1.20(0.6-2.4)$ & $42(0.7)$ & $1.20(0.8-1.7)$ & $1.10(0.53-2.28)$ & $1.40(0.94-2.07)$ \\
\hline \multicolumn{7}{|l|}{ Smoking } \\
\hline Currently & $2(0.4)$ & $2.43(0.6-9.9)$ & $9(1.9)$ & $3.21(1.6-6.3)$ & $1.42(0.17-11.5)$ & $2.68(1.24-5.79)$ \\
\hline Quit & $4(0.2)$ & $1.06(0.4-2.9)$ & $15(0.7)$ & $1.17(0.7-2.0)$ & $1.15(0.34-3.83)$ & $0.91(0.47-1.75)$ \\
\hline Never & $76(0.2)$ & - & $259(0.6)$ & - & - & - \\
\hline \multicolumn{7}{|l|}{ Alcohol } \\
\hline Regularly & $1(0.3)$ & $1.45(0.2-10.5)$ & $5(1.6)$ & $2.71(1.1-6.7)$ & $1.08(0.12-9.27)$ & $2.15(0.79-5.82)$ \\
\hline Occasionally & $33(0.1)$ & $0.59(0.4-0.9)$ & $147(0.6)$ & $0.98(0.8-1.3)$ & $0.52(0.31-0.86)$ & $1.05(0.80-1.37)$ \\
\hline Never & $42(0.2)$ & - & $112(0.6)$ & - & - & - \\
\hline \multicolumn{7}{|l|}{ Anxiety/depression } \\
\hline Yes & $7(0.4)$ & $2.49(1.1-5.4)$ & $13(0.8)$ & $1.25(0.7-2.2)$ & $2.98(1.35-6.58)$ & $1.20(0.65-2.21)$ \\
\hline No & $76(0.2)$ & - & $281(0.6)$ & - & - & - \\
\hline \multicolumn{7}{|l|}{ Prior injuries } \\
\hline One or more & $17(0.2)$ & $1.42(0.8-2.4)$ & $65(0.9)$ & $1.62(1.2-2.1)$ & $1.43(0.80-2.55)$ & $1.65(1.22-2.23)$ \\
\hline None & $65(0.2)$ & - & $217(0.6)$ & - & - & - \\
\hline \multicolumn{7}{|l|}{ Drink-driving } \\
\hline Yes & $8(0.2)$ & $1.15(0.6-2.4)$ & $21(0.5)$ & $0.85(0.5-1.3)$ & $1.25(0.52-3.01)$ & $0.73(0.43-1.23)$ \\
\hline No & $75(0.2)$ & - & $267(0.6)$ & - & - & - \\
\hline
\end{tabular}

${ }^{\mathrm{a} D i p l o m a / C e r t i f i c a t e . ~}{ }^{\mathrm{b}}$ Reference category is being alive by endpoint

Odds ratios in bold typeface are statistically significant at $p<0.05$

Thus, the association between drink-driving and injury mortality in the cohort is supported by a plethora of studies, all pointing to the immediate detrimental effects of alcohol on judgement and motor ability. Historical alcohol consumption therefore may not be a predictor for injury mortality if regular drinkers in the cohort did not engage in alcohol consumption prior to a potential injury hazard, such as before driving. However other studies have found historical alcohol consumption to be a predictor of injury morbidity and mortality, including non-fatal injury in the U.S general population [23] and fatal injury among U.S adults aged above 55 [24].

The association between smoking and injury mortality has previously been observed in literature [15]. This association has been reported to be confounded with alcohol use, however this analysis as well as that of 
Table 4 Multivariate predictors for injury and non-injury mortality among males, Thai Cohort Study

\begin{tabular}{|c|c|c|c|c|c|c|}
\hline & \multicolumn{4}{|c|}{ Univariate $^{\mathbf{b}}$} & \multicolumn{2}{|l|}{ Multivariate $^{\mathbf{b}}$} \\
\hline & \multicolumn{2}{|c|}{ Injury mortality } & \multicolumn{2}{|c|}{ Non-injury mortality } & \multirow{2}{*}{$\begin{array}{l}\text { Injury mortality } \\
\text { AOR }(95 \% \mathrm{Cl})\end{array}$} & \multirow{2}{*}{$\begin{array}{l}\text { Non-injury mortality } \\
\text { AOR }(95 \% \mathrm{Cl})\end{array}$} \\
\hline & n (\%) & OR (95\% Cl) & n (\%) & OR $(95 \% \mathrm{Cl})$ & & \\
\hline \multicolumn{7}{|l|}{ Age } \\
\hline $15-29$ & $75(0.9)$ & - & $47(0.6)$ & - & - & - \\
\hline $30-44$ & $157(0.7)$ & $0.72(0.5-0.9)$ & $238(1)$ & $1.75(1.3-2.4)$ & $0.64(0.46-0.87)$ & $1.57(1.11-2.23)$ \\
\hline $45-59$ & $38(0.5)$ & $0.57(0.4-0.8)$ & $211(2.9)$ & $5.03(3.6-6.9)$ & $0.53(0.33-0.85)$ & $4.29(2.97-6.18)$ \\
\hline $60+$ & $10(1.6)$ & $1.99(1.0-3.9)$ & $79(12.7)$ & $25.08(17.3-36.4)$ & $1.78(0.70-4.53)$ & $18.7(11.7-29.7)$ \\
\hline \multicolumn{7}{|l|}{ Education } \\
\hline Junior High School & $19(1)$ & - & $66(3.4)$ & - & - & - \\
\hline High School & $158(0.8)$ & $0.81(0.5-1.3)$ & $252(1.3)$ & $0.37(0.3-0.5)$ & $0.94(0.48-1.82)$ & $0.73(0.50-1.06)$ \\
\hline Dip./Cert. ${ }^{a}$ & $64(0.7)$ & $0.73(0.4-1.2)$ & $127(1.4)$ & $0.42(0.3-0.6)$ & $0.94(0.47-1.88)$ & $0.91(0.61-1.36)$ \\
\hline University & $39(0.4)$ & $0.45(0.3-0.8)$ & $128(1.5)$ & $0.43(0.3-0.6)$ & $0.65(0.32-1.34)$ & $0.71(0.47-1.06)$ \\
\hline \multicolumn{7}{|l|}{ Region } \\
\hline Central/East & $70(0.6)$ & - & $147(1.3)$ & - & - & - \\
\hline Bangkok & $33(0.6)$ & $0.93(0.6-1.4)$ & $84(1.5)$ & $1.13(0.9-1.5)$ & $1.07(0.67-1.70)$ & $1.01(0.73-1.40)$ \\
\hline North & $53(0.7)$ & $1.12(0.8-1.6)$ & $116(1.5)$ & $1.16(0.9-1.5)$ & $1.17(0.78-1.74)$ & $1.12(0.83-1.52)$ \\
\hline Northeast & $66(0.7)$ & $1.12(0.8-1.6)$ & $164(1.7)$ & $1.32(1.1-1.7)$ & $1.02(0.69-1.51)$ & $1.43(1.09-1.88)$ \\
\hline South & $57(1.2)$ & $1.86(1.3-2.6)$ & $58(1.2)$ & $0.90(0.7-1.2)$ & $1.79(1.20-2.68)$ & $0.97(0.68-1.39)$ \\
\hline \multicolumn{7}{|l|}{ Smoking } \\
\hline Currently & $92(1.1)$ & $1.95(1.5-2.6)$ & $170(2.1)$ & $2.19(1.8-2.7)$ & $1.51(1.08-2.12)$ & $1.92(1.47-2.51)$ \\
\hline Quit & $75(0.6)$ & $1.04(0.8-1.4)$ & $218(1.7)$ & $1.84(1.5-2.3)$ & $0.85(0.60-1.22)$ & $1.29(1.00-1.67)$ \\
\hline Never & $102(0.6)$ & - & $168(1)$ & - & - & - \\
\hline \multicolumn{7}{|l|}{ Alcohol } \\
\hline Regularly & $32(0.8)$ & $1.58(0.9-2.7)$ & $81(2.1)$ & $1.49(1.1-2.1)$ & $1.17(0.61-2.23)$ & $0.97(0.63-1.46)$ \\
\hline Occasionally & $179(0.7)$ & $1.26(0.8-2.0)$ & $301(1.1)$ & $0.79(0.6-1.0)$ & $1.10(0.67-1.81)$ & $0.63(0.45-0.87)$ \\
\hline Never & $22(0.5)$ & - & $59(1.4)$ & - & - & - \\
\hline \multicolumn{7}{|l|}{ Anxiety/depression } \\
\hline Yes & $15(1.2)$ & $1.71(1.0-2.9)$ & $30(2.4)$ & $1.67(1.1-2.4)$ & $1.49(0.78-2.83)$ & $1.71(1.09-2.66)$ \\
\hline No & $265(0.7)$ & - & $545(1.4)$ & - & - & - \\
\hline \multicolumn{7}{|l|}{ Prior injuries } \\
\hline One or more & $67(0.9)$ & $1.44(1.1-1.9)$ & $123(1.7)$ & $1.30(1.1-1.6)$ & $1.28(0.93-1.75)$ & $1.20(0.94-1.54)$ \\
\hline None & $200(0.7)$ & - & $407(1.3)$ & - & - & - \\
\hline \multicolumn{7}{|l|}{ Drink-driving } \\
\hline Yes & $151(0.8)$ & $1.37(1.1-1.7)$ & $235(1.3)$ & $0.81(0.7-0.9)$ & $1.37(1.00-1.87)$ & $0.81(0.64-1.02)$ \\
\hline No & $125(0.6)$ & - & 331 (1.6) & - & - & - \\
\hline
\end{tabular}

${ }^{a}$ Diploma/Certificate. ${ }^{b}$ Reference category is being alive by endpoint

Odds ratios in bold typeface are statistically significant at $p<0.05$

Kawachi et al. (1993) [25] found smoking a significant risk factor for injury death after adjusting for alcohol consumption. Having quit smoking by baseline was not a significant predictor of injury mortality, indicating that personality traits that may cause this association [26] may be changed after quitting smoking. The association between anxiety/depression and injury is often reported in the reverse direction, however the association between anxiety/depression and subsequent injury mortality in the cohort (Table 2) was also seen in a study of adults in a rural American county [14]. Interestingly, we found evidence that this association may be stronger among females. Among males, anxiety/depression was actually significantly associated with non-injury mortality (Table 4), which may be confounded by other serious disease for example. Whilst we found females occasional 
female drinkers having half the odds of injury mortality compared to never drinkers (Table 3), no literature was found evaluating any of these associations by sex in Thailand. Further analysis is required to understand the cause of this association.

The ongoing political violent conflict in the southern region of Thailand [27] likely explains the elevated risk of injury mortality among southern residents in the cohort (Table 2).

Our study is not without limitations. Data for risk factors was obtained at baseline (2005) whilst deaths included in analysis occurred up until 2016. Lifestyle changes may occur in this time period which effect the interpretation of risk factors. However, it should be reiterated that the research aim was to determine long-term risk factors to injury mortality as opposed to immediate risk-factors. The elderly population was underrepresented in our cohort and this should be taken into consideration when reading our findings - the lack of older participants may mean the burden of falls are underrepresented and hence traffic accidents have an abnormally high majority of all injury deaths. Participants were also required to self-report due to the mailed-out questionnaire design of the study, however a large proportion of the cohort reported risk habits such as drinkdriving, so this does not appear to be a major issue. There is still a potential for self-report bias in the data reported here. This could potentially mean that the real prevalence of risk behaviours may be underestimated.

Low socio-economic status was also underrepresented in the cohort, which may influence our results. However, one advantage of our study is that all participants provided their Thai Citizen ID number, allowing us to monitor deaths amongst cohort participants into the future. This will allow for ongoing analysis between baseline risk factors and mortality, and whilst our current analysis of injury mortality lacks enough data on elderly participants for meaningful analysis within this group, this analysis will be possible as our cohort ages. Furthermore, logistic regressions for individual causes of injury deaths will be possible in future analysis when the number of cases is high enough for statistically meaningful analysis. Finally, the analyses presented here are assessing risks and associations with injury from all-causes. The ability to conduct cause-specific analyses was hampered by the numbers in each cause category, and the prevalence of non-specific or unknown injury causes (Table 1).

\section{Conclusions}

There were 363 injury deaths in the Thai Cohort Study between 2005 - 2015. We found that historical drinkdriving but not alcohol consumption was associated with injury mortality, as well as male sex, smoking, anxiety/ depression, and prior injury history. Residing in the southern region of Thailand was a risk factor for injury mortality among males only, whilst the association with anxiety/depression was stronger among females. The association between smoking and alcohol consumption with injury mortality needs to be considered as we found smoking a significant risk factor to injury mortality despite being adjusted for alcohol consumption. The association between residing in southern Thailand and injury mortality may be reflective of political conflict, further research is required to understand this.

\section{Abbreviations \\ AOR: Adjusted Odds Ratio; Cl: Confidence Interval; ICD: International Classification of Disease; ID: Identification; OR: Odds Ratio; SPSS: Statistical Package for the Social Sciences; STOU: Sukhothai Thammathirat Open University; TCS: Thai Cohort Study; U.S: United States; WHO: World Health Organization}

\section{Acknowledgements}

The authors thank the staff at Sukhothai Thammathirat Open University (STOU) who assisted with student contact and the STOU students who are participating in the cohort study.

\section{Authors' contributions}

$\mathrm{CL}$ conceptualised, analysed and drafted the manuscript. MK provided inputs to improve the draft. SS and AS designed and executed the Thai Cohort

Study. All authors reviewed and approved the final submission.

\section{Funding}

This study was supported by the International Collaborative Research Grants Scheme with joint grants from the Wellcome Trust UK (GR071587MA) and the Australian National Health and Medical Research Council (NHMRC) (268055), and as a global health grant from the NHMRC (585426).

\section{Availability of data and materials}

The datasets used and/or analysed during the current study are available from the corresponding author on reasonable request. The lead author signed a data access agreement for use of the Thai Cohort Study dataset.

\section{Ethics approval and consent to participate}

Ethics approval was obtained from Sukhothai Thammathirat Open University Research and Development Institute (protocol 0522/10) and the Australian National University Human Research Ethics Committee (protocols 2004344 and 2009/570). Informed written consent was obtained from all participants upon recruitment at baseline.

\section{Consent for publication}

Not applicable.

\section{Competing interests}

The authors declare that they have no competing interests.

\section{Author details}

'Department of Global Health, Research School of Population Health, Australian National University, 339/4 Hutton St, Acton ACT 2601, Australia. ${ }^{2}$ School of Human Ecology, Sukhothai Thammathirat Open University, Nonthaburi, Thailand.

Received: 24 June 2020 Accepted: 30 October 2020

Published online: 16 November 2020

\section{References}

1. WHO. Injuries and violence: the facts 2014. Geneva: World Health Organization; 2014.

2. Ritchie H, Roser M. Causes of Death. 2018. Published Online at OurWorldlnData.org. Available online: https://ourworldindata.org/causes-ofdeath (Accessed 10 Sept 2020). 
3. Chandran A, Hyder AA, Peek-Asa C. The global burden of unintentional injuries and an agenda for progress. Epidemiol Rev. 2010;32(1):110-20.

4. Yiengprugsawan V, Berecki-Gisolf J, Bain C, et al. Predictors of injury mortality: findings from a large national cohort in Thailand. BMJ Open. 2014 4(6)::004668.

5. WHO. Global status report on road safety 2015. Geneva: World Health Organisation; 2015

6. Haagsma JA, Graetz N, Bolliger I, et al. The global burden of injury: incidence, mortality, disability-adjusted life years and time trends from the global burden of disease study 2013. Injury Prev. 2016;22(1):3-18.

7. Sophonratanapokin B, Sawangdee Y, Soonthorndhada K. Effect of the living environment on falls among the elderly in Thailand. Southeast Asian J Trop Med Public Health. 2012;43(6):1537-47.

8. Porapakkham Y, Rao C, Pattaraarchachai J, et al. Estimated causes of death in Thailand, 2005: implications for health policy. Popul Health Metrics. 2010; 8(1):14.

9. Rao C, Porapakkham Y, Pattaraarchachai J, et al. Verifying causes of death in Thailand: rationale and methods for empirical investigation. Popul Health Metrics. 2010;8:1

10. Pattaraarchachai J, Rao C, Polprasert W, et al. Cause-specific mortality patterns among hospital deaths in Thailand: validating routine death certification. Popul Health Metrics. 2010;8:12.

11. Andreev E, Shkolnikov VM, Pridemore WA, et al. A method for reclassifying cause of death in cases categorized as "event of undetermined intent". Popul Health Metrics. 2015;13:23.

12. Pengpid S, Peltzer K. Alcohol use and misuse among school-going adolescents in Thailand: results of a National Survey in 2015. Int J Environ Res Public Health. 2019;16(11):1898.

13. Patten SB, Williams JV, Lavorato DH, et al. Major depression and injury risk. Can J Psychiatr. 2010;55(5):313-8.

14. Tiesman HM, Peek-Asa C, Whitten $P$, et al. Depressive symptoms as a risk factor for unintentional injury: a cohort study in a rural county. Injury Prevention. 2006;12(3):172-7.

15. Leistikow BN, Martin DC, Jacobs J, et al. Smoking as a risk factor for accident death: a meta-analysis of cohort studies. Accid Anal Prev. 2000:32(3):397405

16. WHO. Thailand's Report on Situation of Severe Injuries 2005-2010. Geneva: World Health Organization; 2012.

17. WHO. Global status report on road safety 2018. Geneva: World Health Organization; 2018

18. Sleigh AC, Seubsman S, Bain C, et al. Cohort profile: the Thai cohort of 87 134 Open University students. Int J Epidemiol. 2008;37(2):266-72.

19. IBM Corp. IBM SPSS statistics for windows, version 23.0. Armonk: IBM Corp; 2015.

20. Taylor B, Irving HM, Kanteres F, et al. The more you drink, the harder you fall: a systematic review and meta-analysis of how acute alcohol consumption and injury or collision risk increase together. J Alcohol Drug Depend. 2010:110(1-2):108-16

21. Watt K, Purdie DM, Roche AM, et al. The relationship between acute alcohol consumption and consequent injury type. Alcohol Alcohol. 2005:40(4):263-8.

22. Peck RC, Gebers MA, Voas RB, et al. The relationship between blood alcohol concentration (BAC), age, and crash risk. J of Safety Research. 2008;39(3): $311-9$.

23. Cherpitel CJ, Tam T, Midanik L, et al. Alcohol and non-fatal injury in the U.S general population: a risk function analysis. Accid Anal Prev. 1995;27(5):651-61.

24. Sorock GS, Chen L, Gonzalgo SR, et al. Alcohol-drinking history and fatal injury in older adults. Alcohol. 2006:40(3):193-9.

25. Kawachi I, Colditz GA, Stampger MJ, et al. Smoking cessation in relation to Total mortality rates in women: a prospective cohort study. Ann Intern Med. 1993;119(10):992-1000

26. Doll $\mathrm{R}$, Peto $\mathrm{R}$, Wheatley $\mathrm{K}$, et al. Mortality in relation to smoking: 40 years' observations on male British doctors. BMJ. 1994:309(6959):901-11.

27. Jitpiromsri S, McCargo D. The southern Thai conflict six years on: insurgency. Not Just Crime Contemp Southeast Asia. 2010;32(2):156-83.

\section{Publisher's Note}

Springer Nature remains neutral with regard to jurisdictional claims in published maps and institutional affiliations.

Ready to submit your research? Choose BMC and benefit from:

- fast, convenient online submission

- thorough peer review by experienced researchers in your field

- rapid publication on acceptance

- support for research data, including large and complex data types

- gold Open Access which fosters wider collaboration and increased citations

- maximum visibility for your research: over $100 \mathrm{M}$ website views per year

At $\mathrm{BMC}$, research is always in progress.

Learn more biomedcentral.com/submissions 